\title{
Essas Mãos: uma experiência teatral com Mulheres em situação de violência doméstica em Minas Gerais (SIAME)
}

Mirela Ferreira Ferraz ${ }^{1}$

Submetido em: 15/04/2020

Aprovado em: 30/10/2020

DOI: $10.5965 / 23580925242020172$

1 Doutora em Teatro pela Universidade do Estado de Santa Catarina (UDESC). E-mail: mihferraz@gmail.com 


\section{RESUMO}

Este relato de experiência apresenta a minha vivência docente no projeto Essas Mãos, realizado no Serviço Interprofissional de Atendimento à Mulher (SIAME), enquanto prática docente no curso de Artes Cênicas - Licenciatura, na Universidade Federal de Ouro Preto (UFOP), em 2010. Sendo assim, são abordados aspectos da memória e procedimentos práticos no exercício da docência em teatro. O referente projeto atendeu mulheres que sofreram violência doméstica e tinha como principal objetivo exaltar a valorização do "ser mulher", tendo em vista o sofrimento de corpos violentados por seus antigos companheiros, através de práticas corporais lúdicas e poéticas. O trabalho teve como principal base a poesia da letrista brasileira Cora Coralina, que fez com que as mulheres participantes, por meio da narrativa, compartilhassem suas histórias de vida para as outras, criando, assim, um espaço de diálogo, escuta, identificação e acolhimento.

Palavras-chave: corpo, poesia, mulheres, violência doméstica, narrativa.

\section{ABSTRACT}

This experience report presents my teaching experience in the project Essas Mãos, has been carried out in Service of Assistance to Women, which was developed during my stage of the Performing Arts course - at Federal University of Ouro Preto (UFOP), in 2010. Therefore, aspects of memory and practical procedures in the teaching of theater are addressed The referent project served women who suffered domestic violence and had as main objective to exalt the valorization of "being a woman", in view of the suffering of violated bodies violated by their former companions, through playful and poetic bodily practices. The work was based mainly on the poetry of the Brazilian lyricist Cora Coralina, which made the 
participating women, through the narrative, share their life stories to others, thus creating a space for dialogue, listening, identification and acceptance.

Keywords: body, poetry, women, domestic violence, narrative.

\section{INTRODUÇÃO}

O século $X X^{2}$ foi marcado pelos estudos que se atentaram a importância do corpo como forma de entender a complexidade humana, traçando contrapontos à teoria cartesiana, que superestimava a mente. Na teoria da psicanálise de Freud, por exemplo, o corpo e sua singularidade foram enfatizados através dos estudos realizados sobre a potência do inconsciente. Já alguns estudos antropológicos e filosóficos apresentam-o como um reflexo de culturas e signos de determinadas sociedades. Michael Foucault, por sua vez, refletiu sobre disciplinarização sofrida pelo corpo, através das relações de poder (biopoder ${ }^{3}$ e biopolítica ${ }^{4}$ ), que de acordo com o autor estão presentes dentro dos sistemas organizacionais por meio da fabricação de "corpos dóceis", enfatizando o controle do Estado em nossas vidas.

Por ser um mediador entre o "eu" e o mundo, o corpo carrega também emoções e lembranças que estão armazenadas na pele de cada indivíduo, de acordo com suas vivências pessoais. Deste modo, o trabalho corporal se torna pertinente, pois busca o autoconhecimento e a percepção do "eu" e do lugar de cada sujeito dentro de uma determinada organização.

\footnotetext{
2É importante considerar, no entanto, que os séculos anteriores foram marcados pela exploração do corpo feminino como propriedade do cônjuge. Além disso, é preciso considerar a teoria cartesiana, que separava corpo e mente, valorizando a supremacia da mente.

3 Segundo Castro (2009) o biopoder estudado por Michel Foucault foi um elemento fundamental para o desenvolvimento do capitalismo. Serviu como uma forma de assegurar a inserção controlada dos corpos no aparato produtivo e para ajustar os fenômenos da população aos processos econômicos.

4 Para Castro (2009) o conceito de biopolítica de Foucault tornou-se uma das formas encontradas pelo governo para buscar um equilíbrio na população, tratando de questões referentes à: saúde, higiene, natalidade, longevidade, raça e etc.
} 
A trajetória da história feminina é marcada por um legado de repressões de séculos, desde a "histerização" de seu corpo até as formas encontradas para o seu domínio, como o controle da reprodução humana. Foucault nos relata essas especulações, as quais marcam as inúmeras codificações que o corpo feminino sofreu, nos apontando a seguinte definição:

\begin{abstract}
Histerização do corpo da mulher: Tríplice processo pelo qual o corpo da mulher foi analisado - qualificado e desqualificado como corpo integralmente saturado de sexualidade; pelo qual, este corpo foi integrado, sob o efeito de uma patologia que lhe seria intrínseca, ao campo das práticas médicas; pelo qual, enfim, foi posto em comunicação orgânica com corpo social (cuja fecundidade regulada deve ser elemento substancial e funcional) e com a vida das crianças (que produz e deve garantir, através de uma responsabilidade biológico-moral que dura todo o período da educação): a Mãe, com sua imagem em negativo que é a "muIher nervosa", constitui a forma mais visível dessa histerização. (FOUCAULT, 1979, p. 98.)
\end{abstract}

Por meio dos estudos foucaultianos é possível compreender a herança cultural que o corpo "reprodutor" da mulher carrega, além de sua "histerização". Justamente por isso, tive o desejo de trabalhar com um grupo de mulheres, que além de trazerem esse estigma cultural e histórico, carregam, ainda, as marcas da violência doméstica, drama que se torna recorrente em muitos lares brasileiros.

\title{
UMA EXPERIMENTAÇÃO PELAS PALAVRAS DA POESIA DE CORA CORALINA
}

O Serviço Interprofissional de Atendimento à Mulher (SIA$\mathrm{ME})^{5}$ é uma instituição sem fins lucrativos mantida pela Universidade Federal de Ouro Preto (UFOP), que busca atender as mulheres ouropretanas que necessitam de assistência jurídica,

50 Serviço Interprofissional de Atendimento à Mulher (SIAME) está localizado na Praça Cesário Alvim, Barra, na cidade de Ouro Preto - MG 
psicológica e social. A instituição procura construir um ambiente familiar, fazendo do local um ambiente caseiro e saudável.

A priori, é importante ressaltar que o referido instituto se trata-se de uma Rede de Enfrentamento à violência contra a muIher, que articula serviços e profissionais em um trabalho articulado. Assim sendo, por ser uma casa direcionada apenas às muIheres, toda a equipe de trabalho é formada por funcionárias, as quais desenvolvem um serviço voluntário na instituição. Ademais, as mulheres que são direcionadas para a instituição foram diagnosticadas por médicos, com alto nível de estresse. Concomitantemente, há aquelas que passaram por algum choque traumático e outras que procuram o lugar como uma alternativa para a convivência social. Contudo, a maioria das mulheres que frequentavam o local eram vítimas de violência doméstica, sendo o motivo mais recorrente. Além do atendimento psicológico, jurídico e social, o SIAME oferece oficinas de trabalhos manuais para suas frequentadoras, que são: corte e costura, pintura de pano de prato, bordado ponto cruz e tricô.

Com a mudança da coordenadoria, o lugar passou por um processo de transformação e algumas características da antiga coordenação ainda continuavam presentes na instituição, apesar das alterações já sofridas. Exemplo disso era um cartaz que estava fixado no corredor da casa que cita algumas regras para a convivência no local:

Aqui neste instituto não é permitido: discórdia, fofoca e a preguiça. Nosso objetivo é ajudar e ser ajudado. Portanto, use seus dons em prol de seu próximo e de si mesmo. Não fale mal de alguém se você não tem certeza, e se tiver, pergunte-se porque está falando isso. Não conseguimos controlar as más línguas dos outros, mas uma vida decente nos capacita a desprezá-las. O mau uso da língua causa graves problemas de saúde, portanto, use-a para saborear as coisas boas e para ajudar alguém, se puder. Não cultive a raiva, o ódio e a inveja, trate o outro como gostaria de ser tratado. Ter problemas na vida é inevitável, ser derrotado por eles é opcional. (SIAME, 2010)

Essas regras ditadas regiam o ambiente, pois apesar de ser 
um centro de convivência que atua com a parceria do poder público, instituições privadas e a sociedade, o SIAME era um local extremamente silencioso e comedido. Essas ordens de controle sobre conversas realçam a ideia que circunda o pensamento popular de nossa cultura ocidental de rotular encontros femininos como "antros de fofocas". Além disso, a valorização exacerbada do silêncio como uma espécie de condição necessária de convivência pode vir a reforçar, ainda mais, a repressão do corpo e o consequente silenciamento da voz, essa que se torna necessária para a denúncia de diversas opressões sofridas. Portanto, a fim de romper com esse silêncio, as nossas mãos, durante a oficina, teceram bordados e vínculos de nossas experiências humanas, enfatizando o dom da narração como parte da vida, dando corporeidade à citação de Benjamin, já que:

O seu dom é poder contar a sua vida; a sua dignidade contá-la por inteiro. O narrador: eis o homem que poderia deixar consumir, com perfeição, a mecha da sua vida na suave chama da narrativa. É nisto que assenta a incomparável atmosfera que envolve o narrador [...] O narrador é a forma na qual o justo se encontra a si próprio. (BENJAMIN, 1992, p. 57)

Considero que a oficina ministrada no SIAME se iniciou a partir de minhas observações, pois foram por meio delas que tive o primeiro contato com a instituição. Pude então, apreender alguns dos costumes rotineiros de lá para descobrir a melhor maneira de me inserir no ambiente. Após as observações iniciais, comecei com um trabalho de divulgação, promovendo o projeto em cartazes e, também, divulgando-o oralmente em todas as oficinas. Com isso surgiram os primeiros questionamentos: Como despertar os possíveis interesses pelo teatro nessas mulheres? Qual seriam os retornos concretos que as práticas teatrais poderiam promover na vida cotidiana delas? Foram por meio desses questionamentos iniciais que optei por não nomear a oficina como "aulas de teatro", pois a prática teatral poderia ser vinculada à imagem de uma ideia popular, a qual compreende a atividade teatral como uma apresentação final, excluindo 
a importância do processo. Por conseguinte, decidi divulgar a oficina como "práticas/vivências artísticas e pedagógicas", procurando sempre explicar cautelosamente como seria o desenrolar das aulas.

Continuei meu trabalho de observação e divulgação percorrendo as oficinas. Havia um pequeno interesse por parte delas em participar do projeto, e aquelas que prometeram frequentar a oficina não compareciam no horário combinado, e não possuíam uma frequência regular. Tive que aprender a lidar com a relutância daquelas mulheres, pois muitas delas não aceitavam nem mesmo participar de uma aula experimental. Com o tempo, eu pude perceber que eram muitos empecilhos que impediam a frequência nas aulas. Essa resistência em não participar começava pelos próprios compromissos de suas vidas domésticas e pelo medo mudar a rotina em que já estavam inseridas. Contudo, as barreiras mais difíceis foram outras: o impedimento de participarem por conta de conflitos familiares, os quais não cediam um tempo para o projeto, e a impossibilidade de participação devida à alta dosagem medicinal, que provocava enjoos e indisposição corporal.

Ao lidar com aquela realidade, pensei em estratégias que permitissem a minha inserção no ambiente. Ao invés de apenas observar as oficinas de trabalhos manuais, passei a frequentá-las. Tentei me colocar somente como uma mulher semelhante a todas dali. Em seguida, eu me adaptei a rotina daquelas tardes e ganhei uma intimidade com os grupos. Assim, pude pensar em outras estratégias que conciliassem o meu projeto político e pedagógico de oficina com a realidade do local.

O ponto de partida que encontrei foi o forte envolvimento que aquelas mulheres possuíam com as mãos, já que trabalhavam com atividades manuais. As mãos trazem em suas linhas e curvas as vivências e a história pessoal de cada uma. Elas significam também um símbolo de trabalho, pois carregam as especificidades da luta de cada mulher, representando-se em expressões populares como: "mãos da roceira", "mãos de costureira", "mãos de cozinheira", entre outras. 
Na poesia de Cora Coralina ${ }^{6}$ encontrei alguns elos importantes referentes ao meu projeto político e pedagógico, que foram questões acerca da identidade, de vivências, caminhos, escolhas e trabalhos. Assim, descobri, por meio da poesia e da narração, um espaço para trabalhar com a prática teatral, que se desdobrou em leituras de poesias. Nossos encontros ${ }^{7}$ foram embalados pelas letras de Cora Coralina e, posteriormente, por diversas poetisas brasileiras, tais como: Cecília Meireles, Adélia Prado, Elisa Lucinda, entre outras. . Cora Coralina, por sua vez, se define em uma de suas poesias como mais doceira do que acadêmica e relata, mediante a sua poética, todas as dificuldades e preconceitos que passou na vida por ser mulher. A simplicidade e a delicadeza da escrita de Cora geraram um processo de identificação naquele grupo, especialmente pela poesia Estas Mãos, a qual inspirou o nome do projeto e serviu como base para todo o nosso trabalho. Nessa poesia, Cora Coralina fala de sua vida de forma humilde e a leitura do poema provocou um reconhecimento imediato em suas ouvintes, as quais se sentiram identificadas e confortadas pela aquela escrita. A semelhança era tão forte que a poesia sempre era lida com frequência, ao ponto de ser repetida algumas vezes durante a tarde.

A poesia Estas Mãos vai além da referência de uma trajetória de vida comum àquelas mulheres, pois a narração poética abriu caminhos para os campos da abstração e subjetivação, despertando a memória pessoal de todas. Assim, a singularidade se tornou mais presente, o que suscitou o despertar de histórias íntimas das envolvidas, através das imagens da poesia. Segue abaixo então, a poesia de Cora:

6 Cora Coralina (1889-1985) poetisa brasileira nascida em Goiás.

7 Os encontros foram realizados semanalmente às quartas-feiras durante o mês de setembro, com duração de sessenta minutos. O grupo era formado por cinco mulheres. Citarei os nomes fictícios dessas mulheres em homenagem às poetisas brasileiras: Cora, Adélia, Elisa, Cecília e Hilda. 


\section{Estas Mãos}

Olha para estas mãos

de mulher roceira,

esforçadas mãos cavouqueiras.

Pesadas, de falanges curtas,

sem trato e sem carinho.

Ousadas e grosseiras.

Mãos que jamais calçaram luvas.

Nunca para elas o brilho dos anéis.

Minha pequenina aliança.

Um dia o chamado heróico emocionante.

- Dei Ouro para o Bem de São Paulo.

Mãos que varreram e cozinharam.

Lavaram e estenderam

roupas nos varais.

Pouparam e remendaram.

Mãos domésticas e remendonas.

Íntimas da economia,

do arroz e do feijão

da sua casa.

Do tacho de cobre.

Da panela de barro.

Da acha de lenha.

Da cinza da fornalha.

Que encestavam o velho barreleiro

e faziam sabão.

Minhas mãos doceiras...

Jamais ociosas.

Fecundas. Imensas e ocupadas.

Mãos laboriosas.

Abertas sempre para dar, ajudar, unir e abençoar.

Mãos de semeador... 
Afeitas à sementeira do trabalho.

Minhas mãos raízes

Procurando a terra.

Semeando sempre.

Jamais para elas

Os júbilos da colheita.

Mãos tenazes e obtusas,

feridas na remoção de pedras e tropeços,

quebrando as arestas da vida.

Mãos alavancas

Na escava de construções inconclusas.

Mãos pequenas e curtas de mulher

que nunca encontrou nada na vida.

Caminheira de uma longa estrada.

Sempre a caminhar.

Sozinha a procurar,

o ângulo prometido,

a pedra rejeitada.

(CORALINA, 2001, p. 62-64)

Por meio dessas iniciativas poéticas, procurei ressaltar a importância de cada uma como protagonistas de suas próprias histórias, o que me fez refletir sobre o pensamento de Foucault a respeito das tantas rotulações feitas sobre o corpo feminino. As mulheres carregam uma forte herança cultural de repressões que permeiam por séculos, com isso o corpo feminino foi, muitas vezes, limitado a certas definições insatisfatórias criando apenas rótulos comuns: "mulher melancia", "mulher objeto", "mulher de malandro", entre outras variações. Faz parte do pensamento de nossa cultura ocidental uma série de características ditas como "femininas", tais como, a delicadeza, fragilidade, amabilidade etc. Assim, cria-se uma ideia geral sobre o assunto, excluindo as inúmeras especificidades existentes no complexo conceito: mulher. A fim de quebrar com esses rótulos, senti a necessidade de trabalhar pela poesia de Cora a singularidade e autonomia daquele grupo. Portanto, com o apoio das leituras 
poéticas, aquelas mulheres passaram contar suas histórias de vida, tornando-se narradoras. Através dessas rodas de diálogo emergiu as histórias pessoais das participantes, as quais se tornaram muito importantes para o reconhecimento de cada muIher na outra. Foi possível perceber o quanto a narração das biografias possibilitou a criação de um clima saudável no ambiente.

As narrações abriram um espaço para a ludicidade e a imaginação, as quais se tornaram um pouco mais presentes na vida daquele grupo. Benjamin (1992) cita, no ensaio "O Narrador", como o excesso de informação se tornou mais presente em nosso cotidiano do que as histórias, pois: "Cada manhã somos informados sobre o que acontece em todo o mundo. E, no entanto, somos tão pobres em histórias maravilhosas!" (BENJAMIN, 1992, p. 34). Compreendo, a partir dessa citação, que a capacidade de recriar a realidade precisa ser estimulada, para que ainda faça parte de nossa rotina cotidiana. Benjamin (1992), ainda, afirma que a capacidade de narração está se extinguindo e, por isso, estamos perdendo, também, uma qualidade que parecia antes inseparável da humanidade: a capacidade de trocar experiências, pois para o filósofo a narração de histórias é proveniente dessa fecunda troca.

Por meio da poesia de Cora estabelecemos ainda um contato com práticas teatrais, que se baseavam em trabalhos corporais realizados em rodas. Trabalhamos, primeiramente, com as mãos, as quais serviram como "portas" para todo o corpo. Desenvolvemos atividades em duplas, que se constituíam nas observações das mãos e, posteriormente, na sensibilidade do toque. Durante esses exercícios de massagem e toque, aventurávamo-nos, também, nas histórias pessoais de cada mulher, as quais se revelavam na espessura da pele, como também em suas linhas. Assim, fomos conhecendo umas às outras através de atividades corporais, que dispensavam a linguagem verbal.

Porém, essa intimidade ocasionada pelas conversas e, principalmente, pela prática teatral, gerava, ocasionalmente, certo constrangimento. Um exemplo dessa dificuldade é o caso de 
M.E $E^{8}$, uma das frequentadoras do SIAME, ela passava por diversos transtornos psicológicos. Há alguns anos, ela perdeu em um acidente dois filhos e, hoje, cuida do outro que sobreviveu, mas que permanece em estado vegetativo. Depois de algum tempo, M.E vivenciou um novo luto com a morte do marido. Logo, ela direcionou toda a sua vida em função de seu único filho. M.E disse que frequenta o SIAME para "desocupar os pensamentos". Em uma tarde ela chegou para a nossa oficina e observou de longe a nossa prática teatral que estava sendo realizada no jardim da casa. Logo depois, voltou imediatamente para a recepção, chorando compulsivamente dizendo: “Eu já disse que não quero fazer terapia, venho aqui pra fazer meu bordadinho e só. Me deixa quieta com o meu bordado e pronto. Já disse que não quero mexer com terapia, não quer" (sic.). Somente depois de um tempo desse ocorrido, por meio de uma conversa informal com a secretária, que descobri esse acontecimento.

Através dessa experiência, pude perceber como a sensibilização para a interiorização, como também, para o contato com o outro, podem ser mais complexas do que aparentam ser, pois, em casos como o de M.E, o veículo do esquecimento pode ser uma saída mais fácil para os enfrentamentos de situações árduas. Mesmo as atividades lúdicas e "leves", com toques e contatos sutis podem estar carregadas de diversas emoções escondidas, as quais podem emergir a qualquer momento. Logo, foi possível compreender alguns dos motivos da relutância por parte daquelas mulheres em participar das atividades. Percebi que o trabalho precisava ser lento e com pouca duração. Consequentemente, procurei investir nas possíveis formas de trabalhar com essa sensibilização arredia tentando focar em uma intimidade menos direta, a qual não precisasse necessariamente do toque. Continuei trabalhando com a literatura poética, para prosseguir com o trabalho de sensibilização e identificação, buscando estimular também o fluido de conversas e das histórias pessoais.

Muitas histórias pessoais que foram contadas eram recorrentes ao passado tortuoso que viveram. Já outras eram diverti-

8 Utilizo-me do codinome M.E para proteger a privacidade da mulher em questão. 
das e foram embaladas por risos e descontrações. Por isso, optei em trabalhar cada vez mais com as suas memórias felizes, as quais conduziam os fios da imaginação e da ludicidade.

O trabalho com as duas vertentes desembocou em um projeto final que foi o nosso "café sarau", o qual encerrou a nossa convivência. O "café sarau" foi realizado em uma agradável tarde de inverno e se consistiu em uma troca, não só de poesias, como também de quitutes. Durante o sarau, pude notar que alguns bloqueios (a timidez e a apatia) foram diluídos. Percebi, ainda, que havia um sentimento de alegria que pairava naquelas reuniões. Naquela tarde, conversamos e lemos poesia. Foi um momento de compartilhamento em que pude notar como elas estavam felizes e confortáveis diante daquela proposta.

Benjamin (1992) cita, em seu ensaio, a importância do trabalho manual na prática da contação de histórias, já que sua origem vem desse específico trabalho. Ele nos afirma:

O papel das mãos tornou- mais modesto e o lugar que elas ocupavam ao narrar ficou deserto (a narração não é, de fato, do ponto de vista físico, só obra da voz). Pelo contrário, na verdadeira narração, as mãos atuam com gestos aprendidos com a experiência do trabalho, os quais apoiam, de múltiplas maneiras, o que vai sendo dito). [...] Sim, podemos ir mais longe e perguntar se a ligação que o narrador tem com a sua matéria - a vida humana - não é, ela própria, uma relação artesanal. Se sua tarefa não consiste, precisamente, em trabalhar a matéria-prima das experiências - as dos outros e as suas próprias - de uma maneira sólida, útil e única. (BENJAMIN, 1992, p. 56)

Inspirada nas palavras de Benjamin (1992), refleti como aquelas mãos representavam suas histórias de vida. O pensamento benjaminiano me fez questionar, também, sobre como o próprio convívio humano pode vir a se tornar matéria artesanal, na medida em que lida com as experiências e com a vida. E se tratando do corpo como matéria, verificamos no trabalho teatral uma das formas de trabalho mais bonita. 


\section{EM VIAS DE UMA POSSÍVEL CONCLUSÃO}

Ao chegar nas linhas finais deste artigo, recordo as angústias vivenciadas durante a oficina Essas Mãos, pois uma série de perguntas sempre me tomavam: estaríamos produzimos algo potente? Será que poderia considerar as nossas rodas de diálogo e leituras como práticas teatrais?

Apesar dessas dúvidas e incertezas, sempre acreditei na energia proveniente do teatro e na força existente nas palavras, principalmente na poesia. Assim, julgo que ocorreram transformações efêmeras na corporeidade daquelas mulheres, que naqueles instantes se portavam mais atentas e dispostas a ler, falar e a ouvir. Levo em consideração, ainda, que tais momentos não aconteciam anteriormente. A roda final de conversa foi outro momento memorável, na qual pudemos trocar experiências. Por meio dessa conversa, percebi que elas estabeleceram um vínculo com o trabalho. Elas me relataram, ainda, que sentiram a falta de nossa prática nos dias em que não pude comparecer. Notei, então, que minha presença já não era "um corpo estranho" no local. Tornamo-nos mais próximas, com o alicerce da condução das palavras de Cora Coralina.

Outra conversa diagnóstica interessante que vivenciei foi com a secretária do instituto, a qual me esclareceu um pouco sobre o ponto de vista daquelas mulheres em relação ao projeto. Ela me relatou que muitas participantes do SIAME possuíam uma visão preconceituosa em relação aos artistas e estudantes de teatro, mas que, com o tempo, elas foram mudando essa visão. Através desse exemplo, percebi como a arte, ainda, é muito marginalizada em nossa sociedade. Sendo assim, tornam-se urgentes a criação de medidas que trabalhem com a formação de espectadores para proporcionar a sensibilização estética dos cidadãos e cidadãs.

Logo, por intermédio dessas conversas finais, pude fazer uma avaliação significativa do meu trabalho. Percebi como a oficina promoveu uma quebra de rotina naquele ambiente de forma positiva, promovendo uma movimentação necessária para a construção de uma energia renovada no ambiente. Além disso, 
considero importante destacar a potências dessas vozes, que foram historicamente silenciadas por anos de opressão patriarcal. Ressalto, sobretudo, a invisibilidade das mulheres negras, as quais possuem pouquíssimos privilégios, na medida em que vivemos numa sociedade marcada pelo racismo e machismo. Pois como cita a autora e ativista Bell Hooks:

Fazer da sala de aula um contexto democrático onde todos sintam a responsabilidade de contribuir é um objetivo central da pedagogia transformadora. [...] À medida que a sala de aula, se torna mais diversa, os professores têm de enfrentar o modo como a política da dominação se reproduz no contexto educacional. Os alunos brancos e homens, por exemplo, continuam sendo os que mais falam em nossas aulas. Os alunos de cor e algumas mulheres brancas dizem ter medo de que os colegas os julguem intelectualmente inferiores. Já dei aula a brilhantes alunos de cor, alguns de idade avançada, que conseguiram, com muita habilidade, nunca abrir a boca na sala de aula. Alguns expressam o sentimento de que, se simplesmente não afirmarem sua subjetividade, terão menos probabilidade de ser agredidos. A aceitação da descentralização global do Ocidente, a adoção do multiculturalismo obrigam os educadores a centrar sua atenção na questão da voz. Quem fala? Quem ouve? E por quê? Cuidar para que todos os alunos cumpram sua responsabilidade de contribuir para o aprendizado na sala de aula não é uma abordagem comum no sistema que Freire chamou de "educação bancária", onde os alunos são encarados como meros consumidores passivos. Uma vez que tantos professores ensinam a partir desse ponto de vista, é difícil criar uma comunidade de aprendizado que abrace plenamente o multiculturalismo. Os alunos estão muito mais dispostos que os professores a abrir mão de sua dependência em relação à educação bancária. Também estão muito mais dispostos a enfrentar o desafio do multiculturalismo. (HOOKS, 2017, p. 56-57).

Por fim, creio que o nosso trabalho promoveu transformações mais momentâneas do que perenes, e isso, eu pude observar a partir das atividades que realizamos em nossos processos de aula. O projeto Essas Mãos transformou-se em pequenas des- 
cobertas, as quais se deram, sobretudo, por meio da poesia de Cora Coralina. Foi com a prática da narração poética que aquelas mulheres puderam, também, narrar suas memórias paras as outras, colocando-se como protagonistas de suas próprias histórias. 


\section{REFERÊNCIAS}

BENJAMIN, Walter. Sobre arte, técnica, linguagem e política. Lisboa: Relógio D'Água, 1992.

CASTRO, Edgardo. Vocabulário de Foucault: um percurso pelos seus temas, conceitos e autores. Belo Horizonte: Autêntica Editora, 2009.

CORA, Coralina. Meu livro de cordel. São Paulo: Global, 2001.

FOUCAULT, Michel. História da sexualidade. A vontade de saber. Rio de janeiro: Graal, 1979.

HOOKS, Bell. A educação como prática de liberdade. São Paulo: Editora WMF Martins Fontes, 2017.

SIAME - Serviço Interprofissional de Atendimento à Mulher, Ouro Preto, Brasil. Disponível em: https://pt-br.facebook.com/ pages/category/Nonprofit-Organization/SIAME-Servi\%C3\%A7oInterprofissional-de-Atendimento-a-Mulher-197804223587703/. Acesso em: 28 de nov. de 2020. 